\title{
Embarazo adolescente y pobreza, una relación compleja
} Teen pregnancy and poverty, a complex relationship

\author{
Gloria Elizabeth García Hernández* \\ Universidad Autónoma Metropolitana Iztapalapa, Ciudad de México, México
}

ISSN: ISSN-OI85-4259; e-ISSN: 2007-9176

DOI: http://dx.doi.org/Io.28928/ri/772014/atcI/garciahernandeze

\section{Resumen}

El objetivo fue revisar, con una metodología cualitativa, las condiciones de vulnerabilidad preexistentes al embarazo, en tres ámbitos de socialización relevantes: familia, escuela y trabajo. Se analizaron 19 historias de vida de mujeres pobres, madres antes de los i8 años, habitantes de la Delegación Iztapalapa. Los resultados permiten concluir que ellas experimentaron importantes desventajas desde la infancia, y que afectaron sus vidas antes del embarazo. Se construyó, para el análisis cualitativo, el concepto de marcador de vulnerabilidad. Palabras clave: madres adolescentes, vulnerabilidad, historia de vida, discriminación escolar, familia.

\section{Abstract}

The main objective was to explore, with a qualitative methodology, the pre-existing conditions of vulnerability before pregnancy by three relevant areas of socialization: family, school, and work. We analyzed Ig life's stories of poor women, mothers before the age of I8, inhabitants of Iztapalapa. The results suggest that these women underwent through important disadvantages since childhood, which is accumulated, and also affected their lives even before pregnancy occurs. It was constructed, for qualitative analysis, the concept of vulnerability marker

Key words teenage mothers, vulnerability, life history, school discrimination, family.

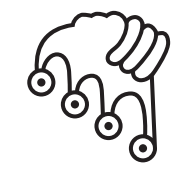

\section{IZTAPALAPA}

Agua sobre lajas

* Profesora-investigadora de tiempo completo en la UAM, Unidad Iztapalapa, División de Ciencias Sociales y Humanidades, Departamento de Sociología. Doctora en Ciencias Sociales con especialidad en Sociología por el Centro de Estudios Sociológicos de El Colegio de México. eligarciah@hotmail.com 


\section{Antecedentes}

n México tomó tiempo establecer la relación entre embarazo adolescente y
nivel socioeconómico. Los resultados de las primeras investigaciones sobre
el tema se generalizaban, sin hacer distinción respecto de esa variable (Stern y García, 200I).

En la actualidad se sabe que la ocurrencia de "embarazo y maternidad adolescentes" varía en los distintos estratos socioeconómicos (Stern, 1995; Stern y Menkes, 2008). De forma similar a lo que sucede en otros países de América Latina, en México la concentración de este fenómeno es de $74 \%$ en los estratos bajos (Stern y Menkes, 2008:377). Cabe señalar que se presenta con mayor frecuencia entre mujeres de 15 y 19 años que en menores de 15 años; esta tendencia se observa también en otros países de América Latina y El Caribe (Gómez, Molina y Zamberlin, 20II).

Se trata de una relación compleja y polémica, pues intervienen, además de las condiciones socioeconómicas desfavorables en que viven las adolescentes, aspectos socioculturales que se traducen en prácticas sexuales y reproductivas avaladas y reforzadas por el contexto. Algunos autores han llegado a considerar que el embarazo es la causa de la pobreza, por asumir que de él se derivan las condiciones desventajosas de las mujeres en la vida futura (Azevedo, Favara y Haddock et al., 2oII; Cameron y Heckman, 1993; Hoffman, Foster y Furstenberg, 1993). El supuesto es entonces que estas mujeres estarán más propensas a ser pobres y sus hijos también.

Desde esta perspectiva, la socialización es un importante mecanismo en la repetición del comportamiento reproductivo; las madres suelen tener actitudes y valores favorables hacia la maternidad temprana de sus hijas (Climent y Arias, 1996; González y Molina, 2007). El embarazo, al correlacionarse con una fecundidad alta (Welti, 2005), es decir, con un mayor número de hijos al final de la vida reproductiva, tiene como consecuencia una familia numerosa, y si esto se combina con los bajos ingresos, las mujeres tienen mayor probabilidad de vivir en condiciones de precariedad. Sucede también que muchas madres adolescentes se quedan solas al cuidado de los 
hijos, con lo que la falta de apoyo económico de la pareja hará disminuir el ingreso de estos hogares (Jacobson y Maynard, 1995).

Otra explicación plantea que las condiciones familiares previas al embarazo y las escasas oportunidades que les ofrece el contexto, y no el embarazo mismo, son en realidad la razón de la pobreza (Geronimus y Korenman, 1992). Kristin Luker (1996), una autora muy crítica sobre la forma como se han relacionado ambas variables, afirma también que, en gran medida, la pobreza es consecuencia de la estructura social y económica en que viven las adolescentes y que no es el embarazo lo que las hace pobres. Señala que para muchas de ellas hay otros factores que generan la pobreza, y que, de cualquier forma, estas adolescentes hubieran sido pobres, independientemente del embarazo en esa etapa de su vida.

Desde este enfoque, el proceso en el que una madre adolescente se convierte en una adulta pobre es extremadamente complejo. Son mujeres que han nacido en la escasez, con poca motivación y poco apoyo de la familia para continuar sus estudios (Geronimus y Korenman, 1992; Luker, 1996). Estas mujeres pobres no tienden a convertirse en motivadas y aventajadas solo con posponer la llegada del primer hijo. Señala Luker que la llegada de un hijo en la adolescencia podrá incrementar en algo su mala situación pero no será la causa de la pobreza (Luker, 1996). Las adolescentes que llevan a término su embarazo lo hacen porque en realidad perciben pocas oportunidades en la vida futura y no ven ningún beneficio en postergar la maternidad (Climent, 2003; Fainsod, 2006).

\section{Embarazo adolescente y familia}

La familia es una instancia mediadora entre la estructura social y las acciones de los sujetos, de particular relevancia cuando se trata de comprender el embarazo y la maternidad en adolescentes porque en ese núcleo se reproducen también las condiciones de clase y género, se construyen, primordialmente, las expectativas acerca de los roles femenino y masculino (Geldstein y Delpino, 1995). Es el ámbito donde se confiere significado social y se regula la sexualidad y la reproducción, la valoración de la maternidad, el matrimonio y la virginidad (Jelin, 1998). Esto lleva a plantear que el embarazo en la adolescencia no tiene una connotación ni una valoración en sí, sino que hay una variedad de situaciones sociofamiliares, aun dentro de un mismo sector socioeconómico, que determinan su significado (Climent, 200I). La composición familiar también parece tener una influencia importante. Arias y Aramburú (1999) identifican como factores de riesgo en el ámbito familiar el hecho de que 
la adolescente viva en una familia desestructurada y conflictiva, o en una donde esté ausente la madre. Las jóvenes que crecen en hogares monoparentales son más proclives a iniciarse sexualmente más temprano (Geldstein y Pantelides, 200I). La calidad de las relaciones familiares es también relevante: una buena comunicación familiar se asocia con menor probabilidad de un inicio sexual temprano (Arias y Aramburú, 1999). En familias pobres se ha visto que la aparente rigidez discursiva de abstinencia sexual absoluta, que los padres demandan de las hijas, con frecuencia contrasta con la falta de control y de autoridad que tienen sobre ellas (Román, et al. 1996). Otros aspectos derivados de la familia que se han relacionado con el embarazo en la adolescencia son el maltrato hacia las hijas y una relación escasa, distante y conflictiva con el padre, así como la presencia de un padrastro (Chávez y Gutiérrez, 2007).

Los estilos educativos de los padres para con las hijas se vinculan con las experiencias sexuales y reproductivas de estas (Climent, 2006). Los padres de las adolescentes que se embarazan suelen ser inconsistentes en el cuidado hacia ellas, ya que enfrentan el dilema de guardarlas demasiado o de no saber protegerlas. Así, la familia puede ser un espacio de protección para las adolescentes, y de apoyo y acompañamiento una vez que se presenta el embarazo, pero también puede ser un ámbito de riesgo y de vulneración que, combinado con otras experiencias, deteriore su vida y amenace su desarrollo y su futuro.

\section{Embarazo adolescente, escuela y trabajo}

En nuestras sociedades existen dos esferas centrales para la construcción de la identidad y para la definición de las trayectorias de los jóvenes: la educación y el trabajo. La falta de acceso a ellos o el acceso deficitario puede dar paso a la vulnerabilidad, la marginación y la exclusión social. En México la deserción escolar ocurre con mayor frecuencia a partir de los I5 años (Imjuve, 2012). La escuela, como espacio privilegiado de socialización, no es neutral, porque reconoce como cultura legítima la de la clase social dominante. Por tanto, da a los alumnos tratos diferenciales según sus distintos orígenes culturales y socioeconómicos (Fainsod, 2006). Como resultado de este proceso, a menudo segrega a los estudiantes de las clases desfavorecidas, $y$ se convierte de ese modo en un dispositivo fragmentador que refuerza la exclusión de amplios sectores de la población.

Para Climent (2003) el fracaso escolar es la experiencia de ineptitud para el desempeño académico, lo que lleva a los sujetos a tener una actitud prescindente 
hacia la escuela. Frente a tales experiencias de fracaso es común que las adolescentes pobres se consideren más aptas para ser madres y amas de casa, por lo que su autoestima positiva se alimenta de esta percepción. Las experiencias de fracaso escolar les confirman sus limitaciones, a la vez que el contexto de pobreza les muestra que, si bien estudiar es importante y socialmente valorado, no es un proyecto al que ellas puedan aspirar. De este modo, su subjetividad se construye en el interjuego de contradicciones que solo pueden superar mediante racionalizaciones y justificaciones como: "la escuela no es para mí" (Climent, 2003). Un antecedente en la trayectoria escolar encontrado por Fainsod (2006) entre las adolescentes que se embarazan es que la mayoría reporta haber reprobado algún grado escolar, cambiado alguna vez de escuela o haber abandonado por algún periodo los estudios. Se trata de trayectorias escolares trastocadas desde antes del embarazo. Hay que tener en cuenta que las características de la familia son determinantes en el progreso educativo de las adolescentes, porque definen el acceso a recursos disponibles para el estudio. Es en la familia donde se genera el ambiente de aprendizaje, las expectativas de los padres e hijos sobre la escuela, la supervisión sobre el desempeño educativo y el seguimiento de su conducta fuera de la escuela; en la familia se define gran parte del capital cultural del que dispone un estudiante. Así, la exclusión del sistema educativo es parte de un proceso de exclusión social más amplio que tiene un fuerte impacto en la subjetividad de las adolescentes. Es muy importante tener en cuenta que en México, a diferencia de lo que sucede en países desarrollados, la mayoría de los embarazos tempranos ocurre después de haber desertado de la escuela (Menkes, Suárez y Nuñez, 2002).

La experiencia de la deserción escolar impone a muchos adolescentes el ingreso prematuro en el mundo del trabajo, sin una formación adecuada y con pocas posibilidades de elección en el ámbito laboral. En el caso de las mujeres, la inserción es más tardía pero ellas se incorporan también tempranamente al trabajo doméstico no remunerado (Horbarth, 2004). La entrada temprana al trabajo se vincula con las condiciones de pobreza; sin embargo, esta inserción está diferenciada por sexo. Ocurre con frecuencia que las mujeres, a pesar de seguir estudiando, se hagan cargo también del trabajo doméstico y del cuidado de los niños en el hogar (Giorguli, 2006). Incluso pueden dejar la escuela para atender los quehaceres del hogar con la misma responsabilidad que una adulta; por lo tanto, suele ocurrir que ellas empiecen a trabajar antes que los varones y sin remuneración económica. También en el campo laboral es importante señalar que entre las adolescentes que han tenido un hijo, en muchos casos su primer empleo antecedió al primer embarazo (Menkes, Suárez y Nuñez, 2002). En el sector popular, Salcedo (2000) encuentra que las adolescentes 
que ella entrevistó ya trabajaban antes del embarazo y que al unirse con la pareja dejaron de hacerlo porque esta ya no las dejó trabajar.

En la articulación del binomio escuela-trabajo, el plan de vida tiene una importancia central. Si bien es necesario considerar que el proyecto vital "explícito" es propio de los estratos socioeconómicos medio y alto, o de aquellos con aspiraciones de movilidad social, en el sector bajo, aunque menos explícitos, existen los proyectos en forma de mandatos y expectativas familiares (Coll, 200I) y la ocurrencia del embarazo es mayor entre las adolescentes que no tienen una perspectiva de seguir estudiando (Tuñón y Nazar, 2002). De esta forma, un hijo puede representar una amenaza en el caso de existir algún deseo de superación académica o abonar al afán de ser madre, por lo que la actitud hacia el embarazo variará en función de esas variables. Las desigualdades socioeconómicas, junto a las expectativas de género, vinculadas a la unión y el embarazo, son, entonces, los factores que determinan los proyectos de vida de las adolescentes en situación de pobreza.

\section{Los conceptos de pobreza y vulnerabilidad}

Cuando se aborda la noción de pobreza existen distintas perspectivas, entre las que destacan las económicas, por lo que su definición depende del enfoque desde el que se aborda y de los criterios que se emplean en su descripción o medición. Existe un acuerdo en definir la pobreza a partir del grado de bienestar alcanzado por un grupo social determinado, frente a la cual otro sector de la población enfrenta carencias; algunos elementos tienen mayor o menor prioridad, dependiendo del enfoque (Townsend, 1979).

Por otra parte, el concepto de vulnerabilidad social se articula con la vivencia de situaciones de fragilidad en la esfera del trabajo, la familia o de otras relaciones sociales significativas. Kaztman (200I) considera que ciertos individuos o familias pobres son más vulnerables que otros en función de la disponibilidad y el uso efectivo que hacen de los distintos activos sociales. Por tanto, más allá de la distinción entre pobres y no pobres, en una sociedad existe una diversidad de recursos que están ligados al acceso diferenciado a los activos sociales, a la fragilización y al riesgo en que viven las personas. Ante una situación imprevista, como un accidente, una enfermedad o un siniestro natural, las personas vulnerables fácilmente pueden transitar al lugar de la exclusión. El desempleo y el bajo nivel escolar favorecen este tránsito y suelen ser importantes desestabilizadores de la sociedad. 
En la literatura sobre vulnerabilidad sobresalen dos enfoques: aquel que la percibe vinculada a situaciones de fragilidad, precariedad, indefensión e incertidumbre, que afectan las posibilidades de integración y movilidad social ascendente (Rodríguez y Villa, 2002), y otro que la asocia al riesgo. En este segundo enfoque se plantea que la situación desfavorecida de una persona o una comunidad es resultado del efecto conjunto ejercido sobre ellas por factores de riesgo de orden múltiple (sociales, económicos, ecológicos, demográficos, epidemiológicos). En ambas propuestas hay particular interés por la capacidad de respuesta o defensa de los sujetos. Ello depende de los activos sociales que posean, los cuales se definen como una amplia gama de recursos o atributos que son movilizados para superar situaciones adversas.

Para los objetivos de este trabajo se tomó como referencia a Castel (1995), quien asume que la pobreza puede convertirse en vulnerabilidad y en exclusión social, en un proceso, algunas veces lento, otras vertiginoso, en el que se van acumulando desventajas en la biografía de las personas. El enfoque de Castel (1995) permite una aproximación al fenómeno de la pobreza, de forma articulada e integradora con el concepto de vulnerabilidad, y no como sinónimos. Citando a Stern (2004) podemos decir que la relación empírica entre estos dos conceptos es contingente. De acuerdo con el modelo explicativo de Castel (1995), una persona pobre no es necesariamente vulnerable, la vulnerabilidad es resultado de la acumulación de desventajas sociales y materiales, que ante una crisis o evento disrruptor, como un accidente o una enfermedad, puede llevar a las personas a la inestabilidad. Sin embargo, frente a las crisis macroeconómicas los pobres son los más vulnerables porque tienen menos recursos para resistirlas, debido a que no poseen seguridad social, no tienen posibilidad de ahorro ni acceso al crédito o a sistemas de seguridad privada (De la Cruz, 2000).

\section{Metodología}

El presente artículo forma parte de una investigación más amplia. ${ }^{.}$Tiene como objetivo explorar las desventajas que experimenta una mujer adolescente antes del embarazo, con la intención de identificar los elementos biográficos vinculados a sus condiciones de pobreza o vulnerabilidad (Castel, 1995). Estos factores o desventajas se exploran en los ámbitos de la familia, la escuela y el trabajo.

I La tesis doctoral de la autora: Embarazo y maternidad adolescentes en contextos de pobreza: una aproximación a los significados de las trayectorias sexuales reproductivas. 
El objetivo del estudio fue identificar, con el uso de una metodología cualitativa, las desventajas presentes en las historias de vida de un grupo de mujeres pobres que fueron madres antes de los I8 años. Se realizó en unidades territoriales de la delegación Iztapalapa, catalogadas con alta y muy alta marginación, esto con la intención de garantizar condiciones de vida similares. Todas las entrevistadas son habitantes de dicha delegación, un contexto caracterizado por crecimiento desorganizado, proliferación de asentamientos irregulares, rezagos en la dotación de infraestructura urbana, escasez de servicios públicos, precariedad en la vivienda, falta de normativa habitacional (Ziccardi, 1998), un escaso control por parte de las autoridades en materia ambiental (Jacobo, Montero, Quintanar, et al. 2005), además de un alto índice de delincuencia organizada (Servín, 2007, Zamudio, 2007). Estas condiciones ubican a la población elegida, en situaciones compartidas de desventaja social, en concordancia con la definición de Townsend (1979).

El trabajo de campo se realizó durante 2005. Las entrevistadas se localizaron directamente en sus domicilios mediante el Atlas socioeconómico y de marginación de la delegación Iztapalapa. ${ }^{2}$ Se contactaron y realizaron un total de 24 entrevistas y se incluyeron solo I9, ya que las seis restantes se hallaban aún en proceso del primer embarazo en el momento de la entrevista y fueron excluidas del análisis. Las conversaciones se grabaron y transcribieron; el texto fue analizado con el apoyo del programa Atlas.ti. Hubo consentimiento informado. Se realizaron en más de una sesión, dependiendo de la disponibilidad de tiempo de las entrevistadas y hasta en tres encuentros, los cuales tuvieron lugar en el espacio elegido por las informantes, siempre en condiciones de privacidad, algunas veces en la casa de la informante, otras en espacios públicos como la calle, pero siempre en el contexto de la entrevistada.

La aproximación metodológica elegida fue la historia de vida, porque permite captar la interrelación entre el horizonte histórico — definido por las coordenadas de

2 Este índice, elaborado por la Coordinación de Planeación del Desarrollo Territorial de la Jefatura de Gobierno del Distrito Federal (COPLADE), se creó con la finalidad de ubicar las zonas de más pobres para atenderlas estratégicamente en sus políticas sociales a través del Programa Integrado Territorial para el Desarrollo Social (PITDs). Las I 352 unidades territoriales del Distrito Federal se clasificaron según cinco grados de marginación: muy alta, alta, media, baja y muy baja (Salcedo, 2004; Salcedo, 2008). En la elaboración del índice se consideraron cuatro dimensiones - educación, ingreso, vivienda y bienes patrimoniales - y seis indicadores de carencias - secundaria incompleta, población ocupada que recibe hasta dos salarios mínimos mensuales, bienes domésticos, estructura de las viviendas, servicios de las viviendas y hacinamiento- (Salcedo, 2008). Sobre la base de esta caracterización se trazaron mapas y zonificaciones de acuerdo con el grado de marginación, lo que dio lugar al Atlas Socioeconómico y de Marginación en el Distrito Federal. En esta expresión geoestadística, la delegación Iztapalapa destaca como la zona con más alta marginación (Salcedo, 2008). 
tiempo y espacio en que vive un sujeto- - la perspectiva micro desde la experiencia y punto de vista de los actores (Correa, 1999). En la historia de vida se reconstruyeron prioritariamente, entre otros aspectos, la experiencia escolar y laboral, así como las relaciones familiares. A continuación, en el cuadro i se muestran con las características de las entrevistadas.

\section{Cuadro i}

Características de las adolescentes entrevistadas

\begin{tabular}{|c|c|c|c|c|c|c|}
\hline & $\begin{array}{l}\text { Entrevis- } \\
\text { tada }\end{array}$ & $\begin{array}{l}\text { Edad } \\
\text { (años) }\end{array}$ & $\begin{array}{c}\text { Edad al 1er } \\
\text { embarazo (años) }\end{array}$ & $\begin{array}{c}\text { Estado } \\
\text { civil }\end{array}$ & $\begin{array}{l}\text { Edad pareja } \\
\quad \text { (años) }\end{array}$ & Escolaridad \\
\hline 1 & Norma & 17 & 16 & unida & 19 & secundaria completa \\
\hline 2 & Olga & 18 & 16 & unida & 22 & $1^{\circ}$ bachillerato \\
\hline 3 & María & 18 & 15 & unida & 26 & secundaria completa \\
\hline 4 & Elena & 17 & 16 & unida & 23 & $2^{\circ}$ secundaria \\
\hline 5 & Teresa & 17 & 17 & soltera & 20 & $2^{\circ}$ de bachillerato \\
\hline 6 & Ana & 17 & 15 & unida & 17 & $2^{\circ}$ secundaria \\
\hline 7 & Guadalupe & 18 & 17 & casada & 20 & $2^{\circ}$ secundaria \\
\hline 8 & Julia & 17 & 16 & unida & 18 & $2^{\circ}$ bachillerato \\
\hline 9 & Patricia & 18 & 17 & unida & 29 & $1^{\circ}$ bachillerato \\
\hline 10 & Marisol & 16 & 14 & soltera & 24 & secundaria completa \\
\hline 11 & Lucía & 17 & 15 & unida & 18 & secundaria completa \\
\hline 12 & Karla & 19 & 16 & soltera & 18 & secundaria completa \\
\hline 13 & Míriam & 19 & 13 & soltera & 22 & secundaria completa \\
\hline 14 & Rosa & 17 & 14 & unida & 20 & $4^{\circ}$ de primaria \\
\hline 15 & Sonia & 15 & 14 & unida & 23 & $1^{\circ}$ secundaria \\
\hline 16 & Beatriz & 19 & 15 & soltera & 24 & secundaria completa \\
\hline 17 & Nora & 18 & 14 & soltera & 16 & $1^{\circ}$ secundaria \\
\hline 18 & Flor & 19 & 14 & soltera & 35 & $1^{\circ}$ secundaria \\
\hline 19 & Dulce & 18 & 14 & soltera & 18 & $1^{\circ}$ secundaria \\
\hline
\end{tabular}


Este enfoque permitió buscar en las historias vitales de las adolescentes los eventos que ellas mismas narraron como experiencias nocivas en la vida, en los tres ámbitos antes mencionados: la familia, la escuela y el trabajo.

\section{Resultados}

La definición de los marcadores de vulnerabilidad fue el resultado de un proceso de ida y vuelta entre la literatura sobre el tema y los datos. ${ }^{3}$ En el ámbito de la familia se construyeron los siguientes marcadores de vulnerabilidad: relaciones familiares no solidarias, presencia en la familia de algún miembro adicto al alcohol o a las drogas, violencia intrafamiliar, separación de los padres, abandono por uno o ambos padres, vida familiar o residencial itinerante y enfermedad o muerte de algún miembro de la familia. En el ámbito escuela-trabajo los marcadores fueron: la deserción escolar anterior al embarazo, dificultades escolares (problemas en la comprensión de algunos temas o materias específicos), reprobación, experiencia de fracaso escolar (sensación subjetiva de ineptitud frente a la escuela), maltrato escolar, responsabilidad por el trabajo doméstico y cuidado de niños cuando aún se encuentra estudiando e inicio laboral mientras se hallan estudiando y anterior al embarazo.

Se debe enfatizar también que algunos de estos marcadores no habían sido reportados antes en la literatura; ejemplo de ello son los hallazgos sobre la importancia de que algún miembro de la familia sea adicto o los casos de maltrato escolar por parte de los profesores. Los marcadores de vulnerabilidad encontrados en estas historias de vida no pretenden ser exhaustivos; se asume que puede haber una infinidad de experiencias que precarizan la vida de una adolescente; sin embargo, en este estudio únicamente se abordan las que se detectaron en estas historias de vida. Respecto de la temporalidad de los marcadores es necesario hacer la aclaración de que todos se ubican en la misma, son eventos experimentados por las adolescentes antes del embarazo. En el cuadro 2 se muestra el registro del total de marcadores de vulnerabilidad encontrados en cada una de las historias de las entrevistadas.

3 Los marcadores de vulnerabilidad se construyeron como un intento de objetivar las experiencias biográficas negativas. El marcador no puede ser visto como una variable o como un factor, sino que implica un elemento constitutivo de la experiencia del sujeto, que es posible rastrear en el relato biográfico. Son marcas biográficas que, desde la perspectiva de las entrevistadas, afectaron de manera importante su vida y se acumulan en forma de desventaja social. Pueden definirse como huellas en el relato biográfico que, acumuladas y a la larga, generaron vulnerabilidad. 


\section{Cuadro 2}

Marcadores de vulnerabilidad en las historias de vida de las entrevistadas

\begin{tabular}{|c|c|c|c|}
\hline & Entrevistada & $\begin{array}{l}\text { Relaciones familiares } \\
8 \text { marcadores }\end{array}$ & $\begin{array}{l}\text { Escuela-trabajo } \\
7 \text { marcadores }\end{array}$ \\
\hline 1 & Norma & $\operatorname{EAP}(I)^{*}$ & DEAE, DE, ME, EFE, ILAE ( 5$)$ \\
\hline 2 & Olga & RFNS, AF (2) & $\mathrm{DE}, \mathrm{R}, \mathrm{EFE}(3)$ \\
\hline 3 & María & RFNS, AF, VI, SP (4) & $\operatorname{DEAE}(\mathrm{I})$ \\
\hline 4 & Elena & RFNS, VI, SP, EAP, VFRI (5) & DEAE, EFE, ILAE, EMSC, ILAE ( 5$)$ \\
\hline 5 & Teresa & RFS, AF, VI, SP, EAP ( 5 ) & $\mathrm{DE}, \mathrm{R}, \mathrm{ILAE}(3)$ \\
\hline 6 & Ana & RFNS, AF, VI, SP, EAP, VFRI (6) & DEAE, ILAE, RTDYCN (3) \\
\hline 7 & Guadalupe & RFNS, AF, VI, VFRI, EF ( 5 ) & DEAE, DE, R, ME, ILAE, RTDYCN (6) \\
\hline 8 & Julia & SP, AP, EF, MFS (4) & DE, R, ME, ILAE (4) \\
\hline 9 & Patricia & SP, AP, VFRI (3) & DEAE, DE, R, ME, EFE, ILAE (6) \\
\hline 10 & Marisol & AF, SP, MFS (3) & DEAE, DE, R, ILAE (4) \\
\hline 11 & Lucía & VI, SP, EAP, VFRI (4) & DEAE, DE, R, ME, EFE ( 5 ) \\
\hline 12 & Karla & RFNS, AF, VI, SP, EAP, VFRI (6) & DEAE, EFE, ILAE, RTDYCN (4) \\
\hline 13 & Míriam & RFNS, AF, VI, SP, VFRI (5) & DEAE, DE, R, EFE (4) \\
\hline 14 & Rosa & RFNS, AF, VI, SP, VFRI ( 5 ) & DEAE, DE, R, EFE (4) \\
\hline 15 & Sonia & RFNS, AF, VI, SP, EAP, VFRI (6) & DEAE, DE, ILAE, RTDYCN (4) \\
\hline 16 & Beatriz & AF, SP, EAP, VFRI (4) & DEAE, DE, R, ILAE, RTDYCN (5) \\
\hline 17 & Nora & RFNS, VI,VFRI, SP, EAP ( 5 ) & DEAE, DE, R, ME, EFE, ILAE (6) \\
\hline 18 & Flor & RFNS, VI, VFRI, MFS (4) & DEAE, DE, R, ME, EFE, ILAE, RTDYCN (7) \\
\hline 19 & Dulce & RFNS, VI, VFRI (3) & DEAE, DE, R, ME, EFE, ILAE (6) \\
\hline
\end{tabular}

RFS - relaciones familiares no solidarias; AF - alcoholismo de algún familiar cercano; vI - violencia intrafamiliar; SP - separación de los padres; EAP - experiencia de abandono de los padres o de alguno de ellos; MFS - muerte de un familiar significativo; EF - enfermedad de un familiar; VFRI - vida familiar y residencial itinerante; DEAE - deserción escolar anterior al embarazo; DE - dificultades escolares; R - reprobación; ME - maltrato escolar; EFE - experiencia de fracaso escolar; ILAE - inicio laboral anterior el embarazo; RTDYCN -responsabilidad de trabajo doméstico y cuidado de niños mientras aún estudiaba.

*Entre paréntesis aparece el número de marcadores que tuvo cada entrevistada en ese ámbito. 


\section{Desventajas previas al embarazo en el ámbito familiar}

\section{RELACIONES FAMILIARES NO SOLIDARIAS}

Con este marcador se alude a la falta de apoyo por parte de los miembros de su familia. En la literatura sobre trayectorias de precariedad se ha visto que si el lazo consanguíneo es endeble, otorga poca seguridad al sujeto y, en un contexto de carencia, lo expone a relaciones de competencia por los escasos recursos, tanto afectivos como materiales, de los que dispone el núcleo familiar (Lewis, 1969). Por otra parte, la falta de ese apoyo puede imprimir en el sujeto una subjetividad subordinada, indefensa y de gran necesidad de afecto. Según Castel (1995) la falta de soportes en el ámbito de la familia está asociada al riesgo de ruptura o desligadura social, que puede conducir primero a la vulnerabilidad y luego a exclusión social.

En las historias de vida, 13 de las entrevistadas relataron experiencias familiares que muestran falta de solidaridad y cercanía, carencia de afecto, así como ausencia de respeto y comunicación entre los integrantes del grupo. La familia, lejos de jugar un papel de apoyo para sus miembros, se convirtió, en estos casos, en un espacio de descalificación o indiferencia referido con mucho dolor:

- Pues, no, no compartíamos... O sea, cada quien su mundo y sus problemas. Si mi mamá acaso nos llegaba a preguntar “‘cómo estás?” o “qué tienes, qué te pasa?”, era porque yo iba y le hacía plática. Mis papás son de las personas que nunca te dicen "te quiero" o nunca te dan un abrazo. “¿Cómo estás?”, yo creo que eso es lo que siempre he querido, que mis papás me digan, que me abracen — con voz más entrecortada-, que mi mamá me diga que me quiere (Olga, I8 años. Se embarazó a los I6 años).

—No, en mi familia era muy pesado el ambiente, ¿eh?, luego, a cada ratito se peleaban, ¿no? Vivíamos todos juntos, pero pu's mis papás dormían separados. Unos comían por su lado, otros por el otro y así... Pesado el ambiente, ¿eh? (Ana, 17 años. Se embarazó a los I5 años).

La familia es el primer espacio donde se ponen en juego los vínculos significativos, las primeras experiencias de aceptación o de rechazo. La falta de aceptación y reconocimiento suele derivar en una experiencia subjetiva de estar solo en el mundo (González de la Rocha, 2005), sin la seguridad que otorgan las relaciones recíprocas de apoyo en una familia solidaria. Giorgi (2006) ha descrito cómo los afectos entre las personas marginadas no suelen verbalizarse; esto, en el caso de algunas de las 
entrevistadas, genera un vacío y una necesidad de recibir expresiones de sentimientos positivos y de reconocimiento. Esta subjetividad fragilizada por la falta de expresiones de afecto y amor en la vida familiar puede llevar a las adolescentes a iniciar una relación de pareja tempranamente, en condiciones de subordinación para lograr el afecto y la aceptación de la pareja (Chávez y Gutiérrez, 2007).

En la vida de estas 13 adolescentes, son escasas las expresiones de afecto por parte de la familia. Llama la atención que cuando se les pidió evocar algún recuerdo agradable de su infancia, la mayoría de ellas narró alguna situación donde la familia estuvo unida. En particular sobresale el recuerdo de alguna Navidad o alguna fiesta como uno de los momentos excepcionales donde ellas sintieron la unión familiar, situaciones en las que experimentaron expresiones de afecto que eran inusuales.

- ¿Cuáles serían algunos recuerdos agradables de tu infancia?

- ¿Que yo me acuerde? Mmmm... ah, pu’s no sé... nada más el día así de la Navidad. Era cuando mi papá se reía. Es que mi papá es muy serio. Pues casi no... pu's no sé... Es que siempre la pasábamos peleando y así... Es que mi papá tiene un carácter muy fuerte, muy agresivo, no sé, muy violento. Por cualquier cosita se enojaba... por eso, casi no... Y nada más en Navidad. Son los únicos días que me acuerdo así, bonitos, porque pu's ya nos abrazamos y todo (Guadalupe, I8 años. Se embarazó a los I7 años).

- ¿Me podrías contar alguno de los recuerdos agradables de tu infancia?

-Ummmm... pu's... no. Ninguno. No recuerdo algo bonito... Mmmm, solo en Navidad, pu's en algunas navidades, son los únicos días en los que nos reunimos todos, en Navidad, y nos dimos un abrazo y platicar, nada más en ese día. Pero sí se sentía bonito que te abrazaban (Olga, I8 años. Se embarazó a los I6 años).

La evocación de una escena familiar agradable las conmueve hasta el llanto y la describen como algo excepcional en su vida. De estas experiencias de falta de apoyo y afecto en la vida familiar puede derivar el sentimiento de desamparo e inferioridad, algo que se ha definido como una estructura yoica débil, con una gran dificultad del sujeto para asumirse desde un yo autónomo (Valentine, 1970). Este enfoque permite poner en perspectiva la idea esencialista que define a las madres adolescentes con baja autoestima, sin preguntarse cómo puede esperarse que tengan una alta autoestima si crecen en condiciones familiares carentes de apoyo y afecto.

El apoyo familiar es una expresión en la socialización temprana que implica la aceptación de los otros significativos y reviste particular importancia para la confirmación continua de la identidad. Para ello se requiere la confirmación explícita y 
emotiva que le brindan esos otros significativos. La aprobación de ellos y la confianza de contar con su ayuda otorga al sujeto una seguridad ontológica y existencial, además de la experiencia de saberse protegido, con la seguridad de que puede contar con los demás para resolver problemas. Por el contrario, en miembros de familias conflictivas y poco solidarias, donde la comunicación está dañada y no se demuestra el afecto, predomina un sentimiento de desprotección, inseguridad y desconfianza (Climent, 2006). Es decir, la calidad de la vida familiar es la clave para el desarrollo del sujeto; más allá de su autoestima, estamos hablando de un bienestar social y psicológico del individuo. Así, la seguridad y la confianza en sí mismo son resultado de un complejo proceso interaccional que no depende de la voluntad del sujeto. Por eso, en este trabajo, la falta de relaciones familiares solidarias se ha construido como un marcador de vulnerabilidad.

\section{Problemas de adicción en algún miembro de la familia}

En las historias de vida de las adolescentes es con frecuencia algún varón de la familia el que presenta conductas adictivas, ya sea el padre, un hermano o algún otro familiar cercano. En diez de las ig analizadas aparece la referencia a un familiar cercano que es adicto. La afectación de dicha conducta es más severa cuando se trata del padre o del padrastro; en cambio, el efecto es menor cuando es un hermano o un tío. También hay un único caso, con severas consecuencias para la vida de la adolescente, donde la madre es alcohólica. La interacción con los varones de la familia que son adictos está mediada por el conflicto $y$, como consecuencia, las relaciones están muy deterioradas y en algunos casos el vínculo se ha roto por completo, y en cualquiera de las situaciones afecta la calidad de vida de las adolescentes y las expone a circunstancias difíciles de manejar a su corta edad.

-Cuando se separaron mis papás, nosotras nos quedamos con mi papá y, pu's, ahí mi papá empezó a tomar. Había veces que luego... no llegaba a la casa. Ya era muy noche y no llegaba, y luego uno de sus compañeros, se puede decir, lo llevaban a la casa bien borracho. O luego nos iban a decir: "Oye, tu papá está en tal lado, está bien borracho, está tirado en la calle". En dos ocasiones a mí me tocó ir por él, porque mi hermana mayor dijo que no - como nada más vivíamos los tres solitos-, entonces dijo que ella no... Entonces, pues yo, la verdad, no me agradaba saber que estuviera ahí tirado... Entonces le pedía de favor a la persona que iba a avisarnos que me llevara y 
me ayudara a ir por él porque pues yo no me lo aguantaba, y ya me acompañaba y ya yo me lo llevaba a la casa (Karla, ig años. Se embarazó a los i6 años).

—No, pu's, de hecho, mi papá es más agresivo... de hecho, él tiene la enfermedad de alcohólico; es alcohólico, él... desde que me acuerdo, diario llega tomado. Llega a echar pleito, a discutir valiéndole gorro todo, esté quien esté... o sea, es, es muy, muy feo vivir con él. De hecho, siendo yo su hija le he dicho que prefiero que se muera a que esté aquí... (llanto). Le he, lo hemos golpeado, por lo mismo,... Yo le tengo un rencor hacia él... No, no lo puedo yo ver, o sea, yo nada más lo tomo así como si fuera un extraño. Yo no quiero que, que mi hija y mi sobrino... vuelvan a sufrir lo que nosotras sufrimos en la... lo que fue la adolescencia y niñez. Pero, pu's, él no, no quiere entender... Según él, me dijo que cuando me aliviara se iba a ir, pero hasta la fecha no lo ha hecho y lo dudo, la verdad, que se vaya (Teresa, I7 años. Se embarazó a los 17 años).

El alcoholismo en algún miembro de la familia se relaciona en los diez casos con una dinámica intrafamiliar sumamente violenta. Sin embargo, las adicciones no están presentes en todos los casos en que hay relaciones violentas en la familia. Según Saraví (2004), las adicciones constituyen un nuevo componente de las condiciones de inseguridad y violencia presentes en los enclaves de pobreza urbana que enfrentan los jóvenes en México, pero en este caso la vulnerabilidad asociada a su presencia se vive también dentro del hogar.

\section{VIOLENCIA INTRAFAMILIAR}

Es importante señalar que la violencia intrafamiliar es un problema social de largo alcance que afecta en forma sistemática a importantes sectores de la población, especialmente a mujeres y menores. Se caracteriza por tener una clara direccionalidad ya que, en la mayoría de los casos, es ejercida por hombres contra mujeres y niños, y de mujeres que son violentadas hacia niños (Sagot, 2000). Las manifestaciones de este tipo de comportamiento incluyen violencia física, psicológica, verbal, sexual y patrimonial. Su impacto en las víctimas es diverso y suele provocar un daño emocional y vulnerar la integridad psíquica, por lo que con frecuencia las víctimas ven afectada su autoestima, su vida productiva y la capacidad para protegerse y para buscar ayuda (Torres, 200I). 
En 13 de los I9 casos aquí estudiados hay relatos de violencia intrafamiliar. Los episodios que se analizan hacen referencia a un complejo sistema de violencia, en donde las madres son maltratadas, pero a la vez ellas lo hacen con sus hijos.

- Me acuerdo que mi mamá sacó un poco de ropa que teníamos, luego nos subimos a un pesero y nos fuimos a casa de mi abuelita. Y yo iba llore y llore porque no quería que mis papás se separaran, pero mi mamá decía que teníamos que irnos porque mi papá le pegaba. Como ella tomaba [alcohol] con sus amigas, él se enojaba y le pegaba. Me acuerdo de ese pleito, cuando nos fuimos que... me acuerdo que fue de un pleito de que mi hermano le aventó un martillo a mi papá. Como de mi hermano mayor no era su papá... de mi papá solo somos yo y mi hermana... Entonces, como no era su papá, entonces mi hermano le pegó porque le había pegado a mi mamá y este... nos tenía encerradas. Entonces ya mi hermano se metió por una ventana y... y lo descalabró a mi papá con el martillo y rápido nos fuimos (Sonia, I5 años. Se embarazó a los I4 años).

—Pues cuando mi mamá se peleaba con mi papá, este... venía... Si nosotros estábamos dormidas, venía mi mamá y nos decía de cosas, este... y nos empezaba a decir que nos paráramos a decirle de cosas a mi papá y si no nos parábamos, nos pegaba, porque decía que... que no la apoyábamos. Es por eso su agresividad... Era muy agresiva. El tiempo que se fue mi papá ya cambiaron las cosas, porque ya no, no fue muy agresiva con nosotras (Teresa, I7 años. Se embarazó a los 17 años).

La dinámica que genera la violencia familiar afecta a las adolescentes, esté o no dirigida hacia ellas, por el simple hecho de formar parte del sistema familiar. En los relatos, las adolescentes muestran una vulnerabilidad emocional asociada a estos hechos violentos, se sienten inseguras y desprotegidas por sus familias. Estas experiencias que amenazan la integridad de los miembros de una familia, pueden estar vinculadas a sentimientos de desamparo y desesperanza (Kersner, 2002). Fue común encontrar la secuencia en donde la madre es violentada por el esposo y ella, a su vez, maltrata a sus hijos. Llama la atención que en las familias monoparentales donde está ausente el esposo de la madre o padre de la adolescente, se encontró que un hermano varón podía ser el perpetrador de la violencia hacia la adolescente.

\section{Separación de los Padres}

En 13 de los 19 casos las adolescentes relataron experiencias negativas respecto de la separación de sus padres. Es de relevancia señalar que en los casos incluidos en 
este estudio, la separación de los padres en familias dominadas por el conflicto puede ser un amortiguador de la violencia intrafamiliar. No obstante, difícilmente se podría afirmar que la separación de los progenitores suponga una experiencia de poca relevancia para estas adolescentes. Los efectos de esta circunstancia tienen que ser leídos en el caso particular de cada familia. Pero más allá de que algunas separaciones amortigüen la violencia en la familia, la ruptura siempre generó cambios en la vida cotidiana de las entrevistadas: se produjo el deterioro de las condiciones económicas de la familia — ya de por sí limitadas-, trajo como consecuencia cambios de residencia continuos, cambios de escuela y hasta la pérdida del año escolar; fue común encontrar que las adolescentes tuvieron que hacer ajustes en la vida derivados de la separación de sus padres. Es de resaltar que entre las entrevistadas, la separación de los padres generalmente tomó la dimensión de hito en sus vidas, es decir, fue vivido como una momento de ruptura, un punto quiebre (Elder, 1985), a partir del cual idealizan la vida anterior - como una vida mejor- en contraste con lo que vivieron después. La forma como los padres manejaron la situacón tuvo consecuencias negativas en la vida de estas mujeres:

—Ese día simplemente nos dijeron: ¿Saben qué? Pus nosotros ya no nos llevamos bien. Tenemos que separarnos, llevar nuestro rumbo cada quien por su lado, este... Pero queremos que ustedes nos digan con quién se van a quedar. De hecho, nos pusieron a mi abuelita también: nos dijeron que si nos íbamos con... con mi papá, mi mamá o mi abuelita. Nos dieron a elegir con quién nos íbamos, porque... entonces, pu's, de hecho yo no me quería ir con ninguno de los tres, y pues yo quería a los dos, tanto a mi mamá como a mi papá. Entonces, pu’s, ¡no!, yo, ¡no! Me sentí, este... sentía que no, sentí que... que todo el mundo se me venía encima. Se me hizo muy difícil quedarme tanto con uno como con otro. Pero entonces, como mi hermana la mayor decidió quedarse con mi papá y ora sí que yo decidí irme con mi hermana. Y no tanto con mi papá pero sí con mi hermana (Karla, I9 años. Se embarazó a los i6 años).

-Con la separación de mis papás, yo ya no tenía apoyo, ya... mis hermanos, también, con sus problemas y todo eso... después que llegamos a vivir con mi papá y su otra mujer... ¡ Uy!, era bien difícil. Como que nosotros no contábamos. Y luego mi hermano se fue... se fue a estudiar a la Marina, y... pues, él era mi apoyo. Me decía: "No, pues, échale ganas... que mira, que esto y lo otro.... Pero, luego, también, que se va. Yo me quedo ahí, sola. Me sentía... ¡no! Yo decía: “ ¡No! híjole, yo ya no salgo de aquí, ya no salgo de esta” (Ana, I7 años. Se embarazó a los I5 años). 
La separación de los padres no siempre ocurre de la mejor forma, ni bajo acuerdos claros que den certidumbre a los hijos. Además, conllevan recomposiciones familiares, por lo que es frecuente que las adolescentes tengan hermanos y hermanas, ya sea de las nuevas relaciones de sus padres o de anteriores. El vínculo padre-hija se ve afectado tras la separación, lo que hace muy complejo para las entrevistadas ubicarse o construirse un nuevo lugar en la familia.

-Con mi papá no, no, ya no nos llevamos, porque... Porque como él vive ya aparte con otra señora, y... y tiene otros hijos más chiquitos. Y él siempre ha dicho de que están primero sus hijos que nosotros. Entonces, pues, ya no contamos con él. Si hasta la última vez que mi hermana se internó, porque estaba entrando en un coma diabético... y ya, nosotros necesitábamos su apoyo, porque... porque mi hermana lo pidió. Preguntaba mucho por él y mi papá no iba a verla. Y le dijo a una de mis tías que primero estaban sus hijos que nosotras (Elena, i7 años. Se embarazó a los i6 años).

Aunque la separación tiene lugar entre los padres, es común que la relación con los hijos se vea alterada y, en ocasiones, se pierda. Las entrevistadas cuyos padres tienen otros hijos viven esto como un remplazo, sobre todo cuando ambos padres se vuelven a unir y procrean más hijos. En algunos casos, las adolescentes habían enfrentado más de una separación de la madre con varias parejas. Tras la separación de los padres, las adolescentes suelen presentar episodios de enojo, malestar y ansiedad.

\section{EXPERIENCIA DE HABER SIDO ABANDONADAS POR LOS PADRES}

La experiencia de haber sido abandonadas por alguno de sus padres fue un marcador de vulnerabilidad que emergió en las entrevistas; antes no ha sido tratado en la literatura sobre el tema. En los relatos de nueve entrevistadas aparece esta experiencia. En algunos casos, las adolescentes fueron encargadas con los abuelos como consecuencia de la separación, porque la madre tuvo que buscar un trabajo en otro lugar. En otros, una nueva unión de la madre fue la causa de que las adolescentes fueran "abandonadas" a la custodia de los abuelos.

El abandono por parte de alguno de los padres es una experiencia subjetiva en donde ellas se sienten echadas a un lado, prescindibles como hijas. Al parecer, es sumamente doloroso el hecho de que un padre, pero todavía más una madre, haya prescindido de ellas. La relevancia del abandono, según algunos teóricos (Santana, 
Sánchez y Herrera, 1998) se vincula con la experiencia de los hijos de sentir amenazada su seguridad. A su vez, se conecta con una falta de capacidad de adaptación a nuevas situaciones, así como a deficiencias para generar condiciones de bienestar psicosocial. El abandono más trascendente en la vida de las adolescentes, según sus relatos, es el de la madre:

-Algo de lo que siempre me acuerdo, fue cuando estábamos, bueno, yo estaba chiquita... todas mis hermanas. Entonces mi mamá nos durmió y me acuerdo que nos dio un beso a las cuatro y nos dijo que nos quería mucho. $Y$ de ahí fue al otro día que ya no estaba: nos había dejado... Dijimos: "Ya nos dejó mi mamá". Nos había dejado ahí, con mi abuelita [...] eso no me deja, no me lo puedo borrar cómo nos abandonó y se fue. Hasta un día le reproché muchas cosas de por qué nos había dejado, hace poco, $y$, pu's, le escupí la cara. Y ahora que tengo a mi hija, me arrepiento, $y$ hasta la fecha no me olvido de lo que hice. Híjole, hasta le pedí perdón... Pero ella me dice que no tengo ni por qué pedirle perdón, que sí es cierto. Porque dice que, de cierto modo, ella se lo merecía. Pero yo sentí feo (Elena, I7 años. Se embarazó a los i6 años).

-Bueno, pues, ahorita, yo siempre viví con mis abuelos por parte de mi mamá y con mi hermano. Siempre fuimos nosotros cuatro, porque mi mamá nos dejó a los dos con mis abuelitos, ajá... De que yo tengo memoria, mis abuelos siempre han sido mis papás. Mi mamá se fue cuando yo tenía 6 años. A esa edad nos dejó, apenas había entrado a la primaria cuando nos abandonó (Julia, 17 años. Se embarazó a los I6 años).

La experiencia de abandono puede variar mucho dependiendo de si hay otros adultos que asumen la paternidad y la maternidad sustitutas. Cuando esto no ocurre, la huella del abandono es más dolorosa para las entrevistadas. Al parecer, esta experiencia las alerta para no hacer algo similar con sus hijos. Esto sale a relucir, en particular, en casos en que las adolescentes tienen problemas con su pareja, pero no se separan con el argumento de que sus hijos serían los más afectados, como consideran que lo fueron ellas cuando vivieron esa situación en carne propia.

\section{VIDA FAMILIAR Y RESIDENCIAL ITINERANTE}

La vida familiar y residencial itinerante es una experiencia de vida que aparece en I2 de los ig casos analizados. Se refiere a distintos movimientos o cambios de casa o de grupo familiar que las entrevistadas han experimentado en su biografía. Esto ocurre 
en particular en los casos donde los padres están separados o ausentes; entonces, ellas son cuidadas en distintas etapas de la infancia y adolescencia por diferentes personas, como pueden ser los abuelos, los tíos, el padre o la madre. Estos cambios suelen alterar su vida afectiva y particularmente su trayectoria escolar. El cambio residencial tiene un significado de inestabilidad entre las adolescentes, las cuales narraron la sensación que tenían de no sentirse bien en ningún lugar, de no tener un espacio de seguridad. En algunos casos, las entrevistadas tuvieron que mudarse a la casa de algún familiar, convivir con abuelos, tíos y primos, quienes no siempre les dieron buen trato. Fueron varias las entrevistadas que dijeron haberse sentido como "arrimadas" en esos hogares. Esto es coherente con la idea de que, cuando los recursos son escasos, un miembro ajeno a la familia se vive como una carga, lo que puede resultar en un rechazo.

-Cuando tuve cinco años, mi mamá... nos había dejado con mis abuelitos, la mamá de mi mamá. Ahí duré cinco años. A los diez me vine aquí, con mi abuelito, y estuve tres años y me volví a regresar con mi abuelita, pero tuve un problema con una de mis tías y me mandaron con uno de mis tíos. Pero ahí también tuve muchos problemas; me decían que nada más estaba ahí de arrimada... Mis primos me decían que yo era una arrimada. Ahí nadie me quería, por eso iban y me aventaban a cualquier lado, me pegaban mucho. Ya después yo decidí venirme con mi mamá, pero ya grande, ¿no? Y con mi mamá también tuve muchos problemas, muchos chismes con su esposo, y ya mejor me decidí a venirme con mi papá otra vez. Aunque no me llevo bien con él porque él sigue tomando, pero ya hasta ahorita aquí sigo (Elena 17 años. Se embarazó a los 16 años).

—No, pu's, una de mi tía me dijo: "Vente conmigo, que tus papás arreglen sus problemas. Tú vente conmigo". Y me fui con ella cuando mis papás se estaban divorciando; y luego ahí tuve problemas y empecé a rodar de casa en casa. Luego con mi mamá y su esposo; y ahora... después, con mi papá (Ana, 17 años. Se embarazó a los 15 años).

Los cambios de casa y de familia tienen consecuencias en la vida escolar de las entrevistadas. En estos casos, los padres o la familia a cargo tomaron decisiones sobre las entrevistadas sin que la seguridad de ellas ni su permanencia en la escuela fuera una prioridad. Estos cambios vulneran la seguridad y la confianza, y pueden afectar el desempeño escolar. También el ámbito personal se ve trastocado al no tener un espacio propio, por precario que este sea. 


\section{ENFERMEDAD O MUERTE DE ALGÚN MIEMBRo DE LA FAMILIA}

Según Coll (200I), la muerte de un familiar afecta de tal forma a la adolescente que busca subsanarla con un hijo. En el análisis de las entrevistas se identificaron cuatro casos de muerte y uno de enfermedad crónica entre los miembros de la familia de las adolescentes. La pérdida y enfermedad de estas personas vulneró directa o indirectamente su vida.

- Pues también... fue cuando se fue mi papá. Ahí fue cuando empecé también... y cuando falleció mi tío, que fue el coraje que me dio de que él sí se haya muerto por... por causa, que no tenía por qué morirse según yo. Sí, yo a él lo quería como mi papá. Cuando mi papá se fue, él fue mi apoyo... Me apoyaba mucho, de hecho, era como mi papá y cuando él se murió yo le... le tuve coraje hacía él porque se dejó vencer por su muerte y porque ya no quería vivir... se supone que yo era una razón para él para vivir... pero no fue así. De hecho, porque él también era alcohólico como mi papá y ya le habían dicho que ya no tomara porque se iba a morir y no hizo caso y, pu's, se fue. Por eso el coraje que a mí me dio de que él me decía que tenía que yo... tenía que vivir y él no quiso vivir. Fue por eso que me dio coraje a mí y fue cuando empecé con la rebeldía (Teresa, I7 años. Se embarazó a los I7 años).

En el caso de una de las entrevistadas, un tío - figura sustituta del padre ausente- muere a consecuencia del alcoholismo. En otro, una abuela - considerada por la entrevistada como una madre sustituta- muere de una enfermedad mal atendida y es cuando la adolescente deserta de la escuela; al poco tiempo se embaraza. El padre de una de ellas también muere a consecuencia del alcoholismo, aunque ya estaba separado de su madre. También se dio el caso del padre de una de las entrevistadas que murió cuando ella era muy pequeña; la joven considera que su vida no hubiera sido tan difícil si eso no hubiera ocurrido. En los casos donde había un lazo afectivo importante las repercusiones de la muerte son de tipo emocional; en aquellos en que se trataba de un proveedor, además hay consecuencias económicas. La enfermedad mental del padre de una de las entrevistadas constituye un caso paradigmático. Guadalupe describe todos los síntomas de una esquizofrenia que su padre ha padecido por años, con importantes consecuencias sobre la dinámica familiar; sin embargo, nunca ha sido atendido porque la familia no percibe claramente que se trata de una enfermedad mental. Esta situación coincide con las observaciones que hace Valentine (1970) sobre el hecho de que la población pobre difícilmente cuenta con alternativas viables para hacer frente a las patologías mentales. 
-Decía que lo correteaban y una vez se llevó a mi hermanito y dice mi hermano que mi papá así se, no sé, empezó a ver otra vez cosas así, que la gente lo seguía y se echó a correr con mi hermanito. Pus mi hermanito traía su herramienta de mi papá: mi papá hasta tiró la herramienta, y pu's mi hermano llegó bien espantado. Dice Rigo que él no veía nada porque mi papá lo jalaba, lo correteaba. Le decía: "Vente, córrele porque me quieren matar". Y pasó el tiempo y ya no quiere salir a ningún lado, a ningún lado. Ya llegamos aquí; ahorita, igual que ya lo perseguían. Decía que ese señor lo quiere matar, lo quiere matar. Pero mi mamá dice que no, dice "no". Hasta mi hermano se desesperaba. Decía: “Ay, papá, ¿cómo cree?”... “Ay, es que ustedes no me creen. No, no los entiendo. Ustedes nomás hasta que me vean muerto", decía mi papá. Y, como ves, hay rollitos de masquin [se refiere a masking tape en los huecos de las paredes de lámina]. ¡Ah!, pu's esos los pusimos nosotros porque de ahí se paraba y se paraba a ver y luego corría para allá, igual ahí y nomás igual corría para acá y veía a los señores y llegaba y se ponía bien nervioso, bien nervioso. "Es que me quieren matar" que no sé qué y nosotros: "No, papá, vamos allá afuera, hay que salir, vamos a pasear". Pero no quería; mi papá andaba pacá y pallá. Luego le decía así a Juan: "Cuídame tú que estás aquí. Cuídenme, no me dejen solo”. Así mi papá decía. Yo, ¡ay!, es que por qué siempre tenía que andar así, siempre andaba pacá; corría así, desesperado... pallá, pacá... Bien mal que se pone mi papá (Guadalupe, i8 años. Se embarazó a los 17).

En este caso particular, la enfermedad del padre está asociada a severas condiciones de violencia familiar; desde la infancia de la entrevistada, hay experiencia de maltrato hacia su madre, hacia ella y sus hermanos. La ignorancia de la familia sobre las enfermedades mentales, les impide buscar ayuda, lo que se combina con la falta de a servicios médicos. La familia no sabe qué hacer con la situación; sin embargo, muchas de las experiencias vividas con su padre dejan en la adolescente eventos dolorosos e incomprensibles para ella.

\section{Marcadores de vulnerabilidad en el ámbito escolar y laboral}

De las I9 entrevistadas, dos tienen estudios de primaria; una de ellas, incompleta; ocho tienen estudios de secundaria incompleta; cinco hicieron la secundaria completa y cuatro cursaron algún semestre en el nivel bachillerato, pero ninguna llegó a completar $50 \%$ de este nivel de estudios. 


\section{Deserción escolar anterior al embarazo}

De las ig entrevistadas, i6 dejaron la escuela antes de embarazarse. La tres que se encontraban estudiando desertaron durante o después del embarazo. Las razones por las cuales lo hicieron son diversas.

Entre quienes el embarazo no fue motivo de deserción, truncaron sus estudios por varias razones. Algunas de ellas evocaron la falta de interés y aburrimiento que les producía la escuela. Otras ubican el motivo de la deserción en su interés por divertirse con sus amigos en actividades ajenas a la escolar. Las "pintas", que fueron denominador común entre las entrevistadas que desertaron con anterioridad al embarazo, consisten en no entrar a clases y en su lugar fugarse con los compañeros o novios a buscar espacios de ocio y recreación, aquellos donde, con frecuencia, ellas consumen alcohol, se encuentran con el novio, se divierten con amigos, van al cine, a plazas comerciales, parques, etcétera.

-Es que nos fuimos varias veces. La primera vez que me fui de pinta, nos cacharon y nos suspendieron casi los 15 días, los últimos I5 días de clases. Entonces, pues, ya no fuimos a la escuela. Ya después nos íbamos de pinta: nos íbamos a la casa de un amigo, nos cambiábamos y nos íbamos al cine (Marisol, I6 años. Se embarazó a los I4 años).

Aunque es común que los padres no se percaten de las "pintas" de sus hijas, en dos casos, cuando las descubrieron y ante las fallidas advertencias, fueron las propias madres quienes las dieron de baja de la escuela al enterarse de su frecuente inasistencia a clases. Aunque también se supo que algunos padres o tutores con quienes las adolescentes tienen mejor comunicación, les daban permiso para que se fueran de "pinta". Sin embargo, no hubo mucha diferencia al final entre las que se escapaban y las que se iban con la anuencia de su familia: de cualquier modo, todas las que se "iban de pinta”, desertaron. La "pinta”, una práctica común en la secundaria, está asociada con bajo rendimiento y reprobación. Varias de las adolescentes se dan cuenta de que eso afecta su desempeño escolar pero les resulta muy difícil dejar de hacerlo por la presión de los compañeros o las amigas. A pesar de que sus padres las regañaban y en la escuela las castigaban, ellas persistieron en esta práctica.

-En la primaria no era problemática, sí estudiaba. Ya después, cuando entré a la secundaria, ahí no. En primero sí iba muy bien, ya cuando entré a segundo fue cuando ya me estaba juntando con mis amigos, me iba de pinta, no entraba en la escuela. Fue cuando reprobé el año. Volví a repetir segundo, iba bien pero no entraba. Entonces, 
otra vez... pues ya mejor me salí. Fue cuando tuve problemas con mi abuelo, fue cuando me volví a regresar con mi mamá (Elena, i7 años. Se embarazó a los I6 años).

En algunos casos, su decisión de dejar la escuela, afirman, se debió al aburrimiento generado por las asignaturas; como pensaron que solo estaban perdiendo el tiempo, consideraron que era mejor ya no asistir. Dos adolescentes son enfáticas en señalar que se salieron por el maltrato que recibían por parte de compañeros y profesores. Otras argumentan que las razones fueron las dificultades enfrentadas para comprender las asignaturas; esto les hizo pensar que no eran buenas para el estudio. Entre todas las adolescentes que desertaron, hubo algunos intentos decididos de volver a la actividad escolar, incluso antes de embarazarse, pero no lo lograron, al parecer porque no tuvieron el apoyo de algún adulto que las acompañara en esta decisión.

\section{Dificultades escolares}

Este marcador se refiere a la experiencia de haber tenido dificultades con algunos contenidos académicos en el proceso de aprendizaje. Algo interesante es que casi todas las adolescentes tuvieron un buen desempeño en la primaria, pero es en la secundaria donde empiezan a percibirse con dificultades para comprender algunos contenidos.

De las I9 entrevistadas, I5 reportaron dificultades escolares. Los problemas con la asignatura de matemáticas fueron generalizados. Refieren dificultades en operaciones como la raíz cuadrada, las fracciones y las ecuaciones. Las entrevistadas dan cuenta de que, lejos de poder aclarar las dudas con los profesores, sus dificultades fueron en incremento; $y$ en algunos casos las hicieron sentir temerosas e inseguras, expuestas a las burlas de sus compañeros e incluso de los profesores.

—Casi no, no, no me gustan las matemáticas, y eso era lo que... No, yo nada más veía llegar a la maestra y yo decía ¡ay, ahí viene! Y era no, pues, era mi terror, pues sentía este... sentía miedo, no sé. Me escondía cuando veía a esa maestra y yo decía “ ¡No!” Ni participaba no, no, nada más pues siempre me dio miedo la maestra de matemáticas (Nora, I8 años. Se embarazó a los I4 años).

De alguna manera, el desenganche de la escuela empieza con estas dificultades, que en algunos casos se superan, siempre y cuando se tenga un apoyo para enfren- 
tarlas. Lo que se observa en las entrevistas es que los profesores no suelen ser muy receptivos a esta situación. Son pocas las entrevistadas que tuvieron en casa alguna persona que les explicara o aclarara sus dudas; generalmente era un hermano mayor, un primo, un tío, rara vez el padre o la madre. En un caso, a una adolescente le ayudaba el "novio" de su mamá, y este fue un caso exitoso en donde ella pudo superar sus dificultades con matemáticas.

En realidad, las familias de estas adolescentes hacen poco por apoyarlas. En el mejor de los casos creen que es suficiente con mandarlas a hacer sus tareas, pero es poco frecuente que las apoyen y les expliquen. Dos circunstancias se suman a este hecho: por un lado, que los padres no manejan estos contenidos académicos y por el otro que no disponen de tiempo para atender a sus hijas. Es en el área artística donde las adolescentes llegan a sentirse con más seguridad. Les gusta participar en bailables o en algunas otras actividades artísticas que comúnmente se realizan en las escuelas públicas.

\section{Reprobación}

Fue un dato común que a las "pintas" y a las dificultades escolares les siguiera la reprobación, con lo que la presencia en la escuela se volvía inestable. De las ig entrevistadas, I2 tuvieron experiencias de reprobación, principalmente en la secundaria.

-En primero estuve en cuadro de honor; en segundo, como que bajé un poquito, como que me gustaba ya más el relajo con mis amigas y todo eso, pero iba bien: llevaba $8 \mathrm{o} 7$. Y en tercero ya fui un fracaso total porque mi abuelo ya no vivía ahí (en la escuela), se jubiló. Entonces, ya en tercero reprobé cuatro materias, me iba de pinta, o sea, yo era un relajo total, porque me desaté toda. Me iba de fiesta con mis amigos (Julia, I7 años. Se embarazó a los I6 años).

Los hallazgos respecto de la reprobación coinciden con lo encontrado por Fainsod (2006), quien reporta que entre las adolescentes que se embarazan, la reprobación suele tener antecedentes que se expresan en dificultades para lo comprensión de algunos temas y en las deficientes prácticas pedagógicas de los profesores. Es interesante encontrar que las adolescentes asuman toda la responsabilidad de su reprobación. No pueden ver el papel que juegan en este hecho las deficiencias de la institución y de los profesores, a pesar de que en múltiples pasajes critican los comportamientos 
de estos. La lógica para asumir la reprobación radica en el hecho de que, si otros logran aprobar, ellas son las únicas responsables de su reprobación.

\section{Experiencia de fracaso escolar}

El fracaso escolar se define en este trabajo como la experiencia de sentirse ineptas para la escuela. Diez de los ig casos analizados reportaron experiencias de esa índole. Si bien este marcador está muy relacionado con la reprobación, no todas las que reprobaron experimentaron fracaso escolar.

- La maestra que me tocó en quinto en la primaria, al principio me regañaba mucho porque no le entendía a las fracciones. Sí, me regañaba y me gritaba, pero ya luego me ponía a pensar y decía: "no, pues, tiene razón la maestra. A lo mejor soy tonta en no entender las cosas" (Norma, I7 años. Se embarazó a los I6 años).

Aquí, la fortaleza y subjetividad de las adolescentes hace la diferencia. En algunas, su fuerza emocional y personal les permite enfrentar las dificultades escolares y la reprobación. La forma en que cobran significado estos hechos puede hacer que una adolescente reprobada no se sienta fracasada en la escuela y busque estrategias para sobreponerse a las dificultades a pesar de no contar con el apoyo necesario. Parece claro que las más vulnerables, las que tienen más desventajas son las que emocionalmente se asumen el fracaso. Ellas deben hacer un mayor esfuerzo frente a los mecanismos marginadores y discriminadores del sistema educativo, que consiste justamente en contrarrestar la deserción. Sin embargo, es muy difícil que logren quitarse de encima la etiqueta del fracaso, por lo que es más fácil prescindir de la escuela. En el momento de la deserción la escuela no es un proyecto o una expectativa a la que ellas aspiren, aunque esta perspectiva siempre cambia con el tiempo.

\section{Maltrato escolar}

El referido maltrato escolar en este caso trasciende el abuso entre compañeros de escuela, ya que se encontró que los profesores también participan activamente. Así que el marcador se refiere a la experiencia de abuso tanto de compañeros como de mentores, prácticas que poco a poco van marginando a la adolescente. Esto tiene que ver con la crítica que se le ha hecho a la escuela de excluir y discriminar a los 
diferentes, a los que se alejan de las normas y de los comportamientos valorados por el sistema escolar. Y aunque el maltrato escolar no está reportado en la literatura sobre embarazo adolescente, hay ocho casos entre las ig entrevistadas que lo vivieron durante su corta estancia en la institución; y, generalmente, entre esas adolescentes que han sido objeto de ese tipo de maltrato también están presentes las dificultades escolares, la reprobación y el fracaso escolar.

Entre las entrevistadas hay un caso paradigmático: se trata de una discriminación por clase, propiciada por los compañeros de la escuela pero alentada y reforzada por el profesor. Guadalupe dice que decidió dejar la escuela porque tenía "muchos problemas con sus compañeros". Al indagar las razones de estos problemas la entrevistada describe que todos se burlaban de ella porque su mamá vendía ajos en los tianguis (mercados ambulantes) de la zona; sin embargo, no comprende el origen ni las dimensiones de la burla, ya que considera que el trabajo realizado por su madre es honesto. A partir de estos sucesos, Guadalupe pasa de la indignación a la confrontación, lo que a la larga la hizo aparecer como una alumna "conflictiva".

- ¿Y en la escuela también tenías muchos amigos?

—En la escuela, mmm... no. En la escuela, casi no. Nomás como unas dos, sí, por lo mismo de que todos se burlaban. Yo decía, pero, pu's, ¿̨por qué?, si en lo que trabaja mi mamá es algo honrado, no es algo malo. Pero sí, quién sabe por qué, pero todos se burlaban de mi mamá y jay!, se pasan de veras.

- ¿Qué te decían?

- Se burlaban de que mi mamá vendía ajos y que no se qué, iAh!, que los de los tianguis que nada más están ahí para estar molestando a la gente. Se burlaban:"Ja, que su mamá vende ajos en el tianguis". Así, cualquier cosa y yo decía ¡ay!, pu’s, ¿por qué? Pus no tiene nada de malo... Por eso casi no, no me llevaba, luego así. O luego me enojaba y sí los pateaba, les pegaba. O sea, a veces soy muy... igual no sé pero, luego dice mi mamá que a la vez soy muy agresiva... Es que también es que no me gusta, así, que se burlen de mi mamá. Y también les pegaba, así, hasta a los hombres también les daba, y luego así, luego me pegaban y me aguantaba de chillar para no demostrarles que, pu's, sí me dolían los trancazos que me daban pero, pu's, no sé por qué eran así conmigo (Guadalupe).

Pero más allá de los problemas con los compañeros, también es un profesor quien ejerce abuso al descalificar su trabajo académico por cuestiones de discriminación de clase: llegó al extremo de no reconocer sus logros y de plagiar su producción. 
Con un discurso disfrazado de motivación a la superación, el profesor descalifica a la madre de la adolescente y a ella misma por su condición de pobres.

-Entonces una vez ese maestro, ve que luego hacen cuentos así para concursos... Entonces, esa vez nos dejaron escribir un cuento. El chiste es que ganó mi cuento y este... y como un día falté me dice mi amiga al otro día: “No, pu’s, ¿qué crees?”, "Que el maestro dijo que Laura va a ir a participar con tu cuento. Y yo me sentí, mal, mal... le digo: “¿Y por qué dijo eso el maestro?” No, dice: "Es que dijo que ella tiene más buena presentación para ir a eso". Y, pu's, yo sentí feo y ya hasta que le dije al maestro: "No pu's, es que, ¿sabe qué? Lo que pasa es que así me dijieron que usté va a mandar a Laura". Dice: "Ah, sí, eso te iba a decir que si mando a Laura para que vaya a ver lo de tu cuento". Le digo "Pero es que no es justo porque ese es mi cuento". El chiste es que el maestro se enojó... fui con el director y le comenté. El chiste es que ni me hicieron caso. ¡Ay!, no, qué feo y esa vez sí me enojé y, pu’s, yo vi mi cuento ahí en su escritorio y se los quité y lo rompí: "Si no voy ir yo pu's entonces nadien va”... El maestro se enojó y ya cuando íbamos a salir de sexto el maestro empezó a decirme que por qué no le echaba ganas a la escuela...que si quiero ser igual que mi mamá vendiendo ajos en los tianguis...yo sí me enojé y le contesté "pu’s que le importa", le dije "si es mi mamá y pu's sí me gustaría ser como mi mamá y dice "Ay, no, pero es que tú tienes que echarle ganas a la escuela para ser mejor que tu mamá". $Y$ yo decía "No, qué tiene de malo". El chiste que ese maestro me cayó re gordo (Guadalupe).4

La idea que subyace en el profesor es que un buen trabajo escolar, sobre todo tratándose de un concurso al exterior de la escuela, no puede ser representado por una alumna pobre, cuya madre vende ajos, a pesar de que se trata de una escuela pública en Iztapalapa, en donde la mayoría de los alumnos tiene una condición de bajo nivel económico. De hecho, la entrevistada relata que ella siempre iba con dinero a la escuela, y que muchos de sus compañeros que no llevaban para gastar en el recreo, pero la discriminación se da por el trabajo que realiza su mamá.

En el caso de Guadalupe, las dificultades escolares, la reprobación y el maltrato escolar son elementos que se van acumulando en su trayectoria hasta que ella decide dejar la escuela, donde no encuentra ninguna motivación; aunado a ello, para su

4 - ¿De qué se trataba tu cuento que ganó?

- Pues, según, de un niño que era, así, pobrecito, y que se encontraba, así, una rana... y que esa rana hablaba, y que la rana le decía que por haber encontrado que... que le iba a dar dinero, que él no quiso, que mejor le pidió un cachito de pan, así cualquier cosa y pues ya no me acuerdo muy bien, pero sí, así más o menos, pero, pu's, ya. 
padre la escuela es totalmente prescindible, a lo que se suman las constantes agresiones que debe enfrentar cotidianamente con sus compañeros.

-Esa muchacha me estaba diciendo un montón de cosas: que era bien maricona, que por qué me dejaba...El chiste que, como no le hice nada, porque yo sí le tenía miedo porque era la que más sabía pelear en la secundaria... no hice nada y me puse a llorar y después le dije a mi mamá. “'Ay!, mamá, es que en la escuela una muchacha me cachetió". Y a mi mamá le dio coraje, dice "Pero, ¿por qué?, algo le has de haber hecho"; le digo: "No, yo no le hice nada", y que se enoja y me dice: "Si yo no te pego, por qué dejas que otros te peguen", dice, “¿Y por qué te dejastes?”... "Pus es que usted me dijo que me iba a sacar si me peliaba". Dice: "No", dice,"Si así como ellas te pegan así, nomás, por pegarte, tú no te vas a estar dejando". Al otro día, me dice mi mamá: "Mira, voy a ir contigo a la escuela y quiero que le pegues a esa muchacha pa que se le quite, pa que no te ofenda, no te siga pegando” “Aay! Pero yo no quería: ¡Ay!, híjole, ¿qué hago?. Y en la salida ahí estaba mi mamá, y yo cuando la vi, yo, ¡híjole! Con el miedo que le tenía a esa muchacha, y el chiste es que nos agarramos. El chiste es que le gané. Hasta eso, le gané, me la desgreñé, y ya llegó mi mamá bien enojada y le dijo a la muchacha "¿Por qué le pegastes a mi hija si mi hija no te hizo nada?" Pus eso te mereces porque a mi hija no le vas a estar pegando". Así le dijo a la muchacha y ya pasó... y también por eso me salí de la escuela (Guadalupe).

Al final, es muy difícil decir por qué se salió Guadalupe de la escuela. En su casa no la apoyaban para seguir estudiando, tenía dificultades con algunas asignaturas, había reprobado, cotidianamente sus compañeros abusaban y se burlaban de ella; los profesores, lejos de brindarle un respaldo y reconocimiento, de motivarla, la descalificaban. Si bien este es el caso más severo de maltrato escolar, en las otras entrevistadas que lo padecieron abundan las injusticias y los abusos de profesores. Es decir, como portadores de un sistema de valores universales promovidos por la escuela, son ellos los principales ejecutores de la segregación de estas estudiantes. En la experiencia de las adolescentes, el abuso más significativo es el del mentor. De alguna manera, frente a los otros estudiantes se sienten con la posibilidad de defenderse o de desautorizar sus opiniones, pero con los profesores, esto es más difícil. Entre los actos de maltrato que vivieron estas adolescentes están los golpes - como aventarles el borrador, darles manazos, jalones de pelo-; o simplemente la actitud de rechazo, porque dicen, ellas sentían que le caían mal a los profesores, lo que con frecuencia generaba que las sacaran del salón, que las castigaran o ridi- 
culizaran frente a los compañeros. Sin duda, el maltrato en la escuela es un factor fundamental en la deserción de estas adolescentes.

\section{Responsabilidad del trabajo doméstico y cuidado de los niños}

En afinidad con los hallazgos de Giorguli (2006), la mayoría de las adolescentes entrevistadas desde muy pequeñas realizan trabajo doméstico a pesar de estar estudiando. Existen diversas modalidades bajo las cuales se realizan estas tareas en el hogar. En algunos casos, se da como una acción de solidaridad con la madre mientras que en otros es por el gusto que les genera hacerlo, y en no pocas ocasiones como una obligación que se asume.

De las I9 adolescentes entrevistadas, a seis les fueron asignadas responsabilidades de trabajo doméstico o cuidado de hermanos menores cuando ellas aún se encontraban estudiando. Esto afectó claramente su desempeño e incluso su asistencia a la escuela se tornó irregular. Otras seis entrevistadas realizaban trabajo doméstico no por obligación pero sí con la conciencia de que su familia, y en particular su madre, necesitaban ese apoyo. Lo que no queda claro en su discurso es por qué asumen que son ellas quienes deben hacerlo, habiendo más hijos u otras hermanas. Con frecuencia, estas entrevistadas aludieron, además, al gusto o placer que encuentran en tener su casa limpia y ordenada.

Dos adolescentes dijeron que no les gustaba el trabajo doméstico; sin embargo, se daban cuenta de que tenían que hacerlo. Tres más no lo hacían porque no se los exigían en sus casas. Definitivamente, las circunstancias familiares influyen mucho para que lo realicen o no; padres o madres ausentes, padres y madres que trabajan y la presencia de hermanos menores en la casa, son algunas de las circunstancias que las llevan a asumir este tipo de práctica.

-Vivía con mi papá y con mi hermana, nada más vivíamos los tres solos; yo me dedicaba a lo que eran los quehaceres de la casa; mi hermana mayor se dedicaba a lo que era lavar o hacer la comida; mi papá... en ese tiempo se dedicó a trabajar en una bici-taxi. Nos llevaba las cosas para la comida; o luego nos llevaba a comprar a nosotras las cosas del mercado, nos regresaba a la casa y se iba otro rato en lo que hacíamos nosotras la comida. Bueno, mi hermana mayor era la que hacía la comida (Karla, I9 años. Se embarazó a los I6 años). 
- Luego hubo un tiempo en, cuando mis papás se metieron a trabajar, yo cuidé a mis hermanos. Pus yo iba a la escuela, este... firmaba sus boletas, así, en fin, iba a ver cómo iba y todo eso.

- ¿Y cómo te sentías con eso?

—Bien (risa), sí, sí me gustaba, porque, bueno, a lo mejor y eso me ayudó ¿no? Que cuando yo me junté pues no, no estaba tan desubicada en lo que era un, un matrimonio y todo eso, que también o sea, el casarte y todo, pues... te da, tener obligaciones con los hijos, todo eso. Bueno, eso me ayudó mucho, en... mi relación con mi pareja ¿no? Sí, sí me gustaba (Beatriz, ig años. Se embarazó a los I5 años).

Desde la perspectiva de Espíndola y León (2002), las mujeres pobres pierden en experiencia laboral el tiempo que sus pares ganan al insertarse directamente en el trabajo formal. Sin embargo, esto depende de las expectativas y las oportunidades reales que tengan en la vida. Algunas consideran que las responsabilidades del trabajo doméstico y el cuidado de niños las preparó para cumplir con el rol de esposas y madres que adquirieron a muy temprana edad. El punto aquí es que si ellas realmente tuvieran otras opciones accesibles, distintas al matrimonio y a la maternidad, probablemente no valorarían de la misma forma su incursión temprana en el trabajo doméstico. Tal vez este tendría un valor más relacionado con la formación de hábitos y no tanto con la asunción de una responsabilidad u obligación de género basada en la división sexual del trabajo. Este último punto hace muy discutible la diferencia en el trato que algunas de estas adolescentes tienen en el grupo familiar ya que, teniendo hermanos varones coetáneos, es a ellas a quienes se les exige que los atiendan, les den de comer, les tengan lista la ropa para cuando ellos la ocupen. Esta desigualdad de género es asumida con naturalidad tanto por las adolescentes como por sus familias.

\section{Inicio laboral anterior al embarazo}

El trabajo remunerado puede tener distintos significados y consecuencias en la vida de las entrevistadas. En 13 casos las adolescentes obtuvieron un trabajo remunerado antes del embarazo. A pesar de las condiciones familiares de carencia y precariedad de todas las adolescentes, no son los padres quienes las presionan para comenzar a trabajar sino que, en general, la iniciativa es de ellas. Por supuesto, se trata de una iniciativa que, por lo regular, los padres — particularmente las madres - respaldan y hasta gestionan. Los motivos de las adolescentes para entrar a trabajar van desde 
el deseo de tener más independencia de su familia, de comprarse ropa y artículos de uso personal que sus padres no les pueden dar $y$, en pocos casos, para ayudar a su mamá, quien generalmente trabaja. Cuando se exploró el tipo de "cosas" que aspiran a comprar con su ingreso, ellas se refieren a insumos modestos, como champú, cosméticos, ropa, golosinas y otros antojos. Una vez que trabajan el ingreso no se destina a cubrir gastos de la escuela; esto ocurre con algunas excepciones y en periodos muy específicos. Solamente en tres casos las adolescentes aportaban algo al gasto familiar."Me gustaba trabajar porque ya me compraba mis pantalones, me compraba mis zapatos, mis blusas, todo. Y luego me salía de trabajar pero ya tenía yo las cosas. Ya cuando no tenía ya ropa otra vez me metía a trabajar, y asi” (Flor, 19 años. Se embarazó a los I4 años).

Las actividades en las cuales ellas se inician laboralmente tienen una fuerte carga de segregación por género, es decir, se trata de actividades estereotipadas como femeninas: quehaceres domésticos, en casas o en negocios, y el cuidado de niños pequeños. Las actividades de ese inicio laboral varían: empleada o vendedora en algún negocio como zapatería, juguetería, tienda de regalos, puesto en el mercado, o en una tortillería, entre otros. Las condiciones son totalmente informales y sin prestaciones, con salarios definidos arbitrariamente por el empleador. La relación laboral depende más de la voluntad del empleador que del derecho, lo cual se vincula a que son menores de edad. Solamente en un caso a la adolescente fue adisetrada desde muy pequeña para valorar el trabajo como un recurso útil para la vida.

-Desde los siete años, mi abuelo me enseñó a trabajar. Como toda mi familia trabaja en un tianguis, ahí me puso desde los siete años mi abuelito. Pero yo sola en mi propio puesto de burbujas, así, burbujas para los niños, con el jabón las hacíamos, de jabón. Me puso ahí una caja con mis burbujas y “vamos, m’ija, póngase lista”. Nomás me iban a veces a vigilar, me daba mis vueltas, pues como yo ya sabía hacer cuentas, pues era más fácil para mí, ¿no? y sí aprendí (Norma, 17 años. Se embarazó por primera vez a los 16 años).

-Yo le dije a mi mamá que quería trabajar y me dijo: "Ah, ¿y a dónde te vas a ir a trabajar?" Y yo dije: "Pues, no sé" y ella, pues, conoce a varias personas, y una de sus amigas tiene un taller de costura. Entonces me dijo: "Pues si quieres, le digo". Y ya le dijo y me fui como... estuve como un mes ahí trabajando. Me ponían a deshilar pero me pagaban muy poquito: iba tres días a la semana y me pagaban iıo pesos por tres días. Entonces, pues, ya ese dinero que yo me ganaba ahí me lo gastaba en lo que yo quería. Ese fue mi primer trabajo (Marisol, I6 años. Se embarazó a los I4 años). 
La menor edad de inicio laboral es de siete años. En este caso, la experiencia de trabajo temprano fue positiva, ya que el abuelo tenía el cuidado de que esto no afectara las responsabilidades escolares y a la niña le gustaba hacerlo. En cambio, hay otras experiencias donde las condiciones laborales son totalmente precarias, con ingresos mínimos y en condiciones de abuso.

-Empecé a trabajar en una fábrica de gelatinas. Nos explotaban pero feo, porque había veces que nos teníamos que quedar y eran horas que no nos pagaban, con el peligro que nos fuéramos a quemar con la grenetina caliente. Luego, teníamos que subir un segundo piso con botes de gelatina caliente y luego se regaba en el piso, bajar escaleras y demás; era muy peligroso (Karla, I9 años. Se embarazó a los I6 años).

Los significados que las adolescentes asignan al trabajo son diversos. La mayoría lo ve como una necesidad, son pocas las que lo contemplan como una forma de desarrollo personal. Hay adolescentes que lo hacen por un afán de ser más independientes. Esto puede tomarse como un signo de autonomía. Sin embargo, hay otras que se inician más por obligación que por gusto. Esto ocurrió particularmente con las adolescentes que antes del embarazo no habían trabajado y tuvieron que hacerlo para cubrir las necesidades básicas del hijo.

\section{Conclusiones}

Los hallazgos de este estudio, de carácter cualitativo y exploratorio, sugieren que no es el embarazo lo que nos permite explicar la vulnerabilidad acumulada en la biografía de las adolescentes: en sus historias de vida aparece la pobreza en la experiencia cotidiana y desde muy temprana edad, como factor que va dejando sedimentos de precariedad. El análisis de los marcadores permitió darle contenido a ese elemento, y entender cómo tuvo lugar la acumulación de desventajas. La experiencia de vida de las entrevistadas muestra la forma como intervienen instancias mediadoras en este proceso, tales como la familia, la escuela, y el trabajo. Las condiciones de vida que los padres pueden ofrecerles, en un contexto marcado por la pobreza, en el que predominan las situaciones laborales inestables, problemas de adicción, esquemas culturales conservadores y relaciones de género inequitativas, difícilmente pueden abrirles opciones distintas a la maternidad.

Se podría decir que las condiciones que enfrenta las mujeres pobres cuando se embarazan ya vienen muy determinadas por sus experiencias en la socialización 
primaria, aunque estas se exacerban cuando las adolescentes transitan a la maternidad con pocos recursos para enfrentar la vida adulta.

Podemos decir que en el ámbito de la familia se origina la construcción de una subjetividad frágil, marcada por la falta de reconocimiento de los otros significativos como son los padres. La infancia de las adolescentes estudiadas se caracterizó por la inestabilidad familiar y la falta de apoyos en una etapa de la vida determinante para su devenir, tanto en lo intelectual como en lo económico y lo emocional.

El ámbito escolar es el principal espacio donde viven la exclusión. Al conjugar el déficit de educación que tienen en sus hogares con las dificultades escolares, el fracaso escolar y el maltrato y la discriminación que sufren, muy pronto se ubican en el camino de la deserción escolar, lo que las relegará al quehacer doméstico o a un trabajo remunerado pero en condiciones de precariedad laboral.

Frente a los enfoques en que se responsabiliza del embarazo adolescente prioritariamente a las mujeres adolescentes por las malas elecciones que hacen en sus vidas, el análisis realizado muestra que las acciones y decisiones individuales no ocurren en un vacío cultural, sino que hay un contexto interaccional que prescribe, respalda, anima y posibilita que las mujeres tengan pronto un hijo. En un contexto de pobreza y vulnerabilidad, el embarazo es un evento de tal fuerza simbólica que puede reconfigurar un proyecto de vida y subsanar las experiencias negativas del pasado, reinventar al sujeto y fortalecer su identidad. Desde la experiencia de los sujetos, "ser alguien en la vida" es una experiencia más cercana al embarazo y la maternidad que al estudio y el trabajo.

Una mención especial merece el tema del embarazo frente a la deserción escolar, ya que, al menos en la población estudiada, la regularidad fue que las adolescentes abandonaran la escuela antes de que ocurriera el embarazo y por razones muy ajenas a este. En este hecho, el sistema escolar y sus actores, principalmente los profesores, juegan un papel trascendental en la decisión de permanecer en la escuela. Si la actividad académica se convirtiera en un espacio de logros y reconocimientos, por pequeños que estos fueran, podría motivar la permanencia y el buen desempeño escolar, pero lejos de esto, las adolescentes describen a profesores incompetentes y con poca capacidad crítica sobre el papel que juegan como operadores de la discriminación y la exclusión.

Por otra parte, se encontró que las desventajas en las relaciones familiares tienen un correlato en el ámbito de la escuela, lo que lleva a plantear como hipótesis que una familia que no sostiene emocionalmente al sujeto, difícilmente lo apoya y estimula en su desempeño escolar. De acuerdo con los resultados del análisis que aquí se expone, los dos ámbitos que resultan afectados en prácticamente todas las 
historias de vida son la familia y la escuela. En condiciones como las descritas en el contexto estudiado cabría preguntarnos ¿Cómo puede un padre alcohólico, sin trabajo y sin recursos emocionales para demostrar su afecto, apoyar el desarrollo de su hija adolescente? ¿Cómo puede una madre que vive violencia doméstica transmitir seguridad y respaldo a su hija adolescente? ¿Cómo puede una adolescente, que es discriminada y se aburre en la escuela, sobreponerse a las dificultades académicas para sostener un proyecto vida diferente a la maternidad?

Así, en la relación entre pobreza y embarazo adolescente existen múltiples elementos socioculturales que constituyen fuentes de vulnerabilidad en las biografías de estas adolescentes, entre los cuales destacan, en coincidencia con Fainsod (2006), las limitaciones que en el mundo simbólico cierran la posibilidad de decisiones autónomas y que involucran modos de dominación hacia las mujeres y hacia los pobres, que generan una deficiencia en la autonomía psíquica de las adolescentes para decidir tener o no relaciones sexuales, y tener o no un hijo. Esto, en el entendido de que para desarrollar estrategias de autocuidado es necesario poner en juego un conjunto de recursos cognitivos, económicos y relacionales de los cuales muchas adolescentes pobres carecen.

Si bien la maternidad adolescente puede verse como un vehículo de reproducción de pobreza, esto no equivale a decir que es su causa ni que es el único factor que desencadena su repetición. Se trata más bien de múltiples situaciones ligadas a la escolaridad, el trabajo y la familia, que se traducen en oportunidades o limitaciones sociales, económicas e incluso culturales de las mujeres que se convierten en madres adolescentes. La presente investigación aporta información que permite mirar la relación entre el embarazo adolescente y las condiciones de vida en la pobreza de una manera compleja. Al parecer, la vulnerabilidad juega un importante papel en esta relación y muestra cómo en las condiciones de vida más desventajosas, el embarazo se suma como un evento más en la espiral de una exclusión que se ha iniciado en realidad mucho antes, desde la infancia. De la misma manera, seguramente estas condiciones también se reproducirán y tendrán consecuencias en la vida de sus hijos, y en la de los hijos de sus hijos.

Para finalizar, se hace necesaria una última reflexión del embarazo adolescente y la desigualdad de género. Las adolescentes suelen tomar decisiones sexuales y reproductivas en un complejo entramado que articula su clase social y su condición de género, por lo que es necesario asumir que el embarazo y la maternidad adolescentes están relacionados con la desigualdad social, lo que implica no solo analizarlos en términos de estructura de clase sino abordarlos complementariamente desde una perspectiva de género, ya que las estructuras de género suponen una norma- 
tiva diferenciada para varones y mujeres, para jóvenes y adultos, y para casados y solteros, lo que se traduce en desigual acceso de los sexos al poder y a los recursos (Szasz, 1998). Por tanto podemos decir que la construcción social del género es fundamental en el proceso del embarazo adolescente. Los comportamientos sexuales de las adolescentes están determinados, en gran medida, por relaciones de poder asimétricas que vulneran sus decisiones y su capacidad de negociación sexual. El marco de acción que rige su comportamiento, con frecuencia, se ciñe a los límites de los estereotipos masculinos y femeninos. Así, por su alta valoración la maternidad y la vida conyugal se convierten en las opciones viables para el reconocimiento social, quedando de lado otros proyectos de vida. Tener un hijo lo antes posible en la vida es entonces una valiosa fuente de poder que potencialmente reivindica a las mujeres frente a la comunidad.

Podemos ver también que los marcadores de vulnerabilidad se asocian claramente con la condición de género de las adolescentes. En el ámbito de la familia la subordinación de las adolescentes por ser mujeres se expresa claramente en la distribución sexual del trabajo, ya que es común que desde pequeñas se les asignen tareas tradicionalmente femeninas en detrimento de su desempeño escolar. Por otro lado, en la inserción laboral temprana también ellas tienen una desventaja ligada a su género, que se traduce en una pobre valoración y remuneración de su trabajo.

\section{Bibliografía}

Arias, Rosario y Carlos Aramburú

1999 Uno empieza a alucinar. Percepciones de los jóvenes sobre sexualidad, embarazo y acceso a los servicios de salud, Redess Jóvenes, Fundación summit, Perú.

Azevedo, Joao Pedro et al.

20II Embarazo adolescente y oportunidades en América Latina y el Caribe. Sobre las decisiones de fecundidad Adolescente, la pobreza y los logros económicos, Banco Mundial, Washington DC, 174 pp.

Cameron, Stephen y James Heckman

1993 "Nonequivalence of high school equivalents", Journal of Labor Economics, I(II), pp. I-47.

Castel, Robert

1995 "De la exclusión como estado a la vulnerabilidad como proceso", Archipiélago. Cuadernos de crítica de la cultura, 2I, pp. 27-36. 
Chávez, Ana María y Raquel Gutiérrez

2007 "Antecedentes psicosociales que influyen en la ocurrencia del embarazo en adolescentes" Acta Universitaria, I7(3), septiembre-diciembre, pp. 48-56.

Climent, Graciela y Diana Arias

I996 "Estilo de vida, imágenes de género y proyecto de vida de adolescentes embarazadas" Revista de la Sociedad Argentina de Ginecología Infanto Juvenil, 3(2), pp. 47-56.

Climent, Graciela

2001 "Maternidad adolescenteः ¿Una situación conflictiva?", ponencia presentada al XXIII Congreso de la Asociación Latinoamericana de Sociología, Guatemala, 29 de octubre al 2 de noviembre.

2003 "La maternidad adolescente, una expresión de la cuestión social. El interjuego entre la exclusión social, la construcción de la subjetividad y las políticas públicas" Revista Argentina de Sociología, I, pp. 77-93.

2006 "Representaciones sociales, valores y prácticas parentales educativas: perspectivas de madres de adolescentes embarazadas", Revista de Estudios de Género. La ventana, 23, pp. 166-213.

Coll, Ana

$200 \mathrm{I}$ "Embarazo en la adolescencia ¿cuál es el problema?" en Solum Donas (comp.), Adolescencia y juventud en América Latina, Libro Universitario Regional, Costa Rica, pp. 425-445.

Correa, Rosario

I999 "La aproximación biográfica como opción epistemológica, ética y metodológica” Proposiciones, 29, pp. 35-44.

Cruz Gallegos, José Luis de la

2000 Salarios, empleo y pobreza en México, tesis de maestría inédita, El Colegio de México, México.

Elder, Glen

1985 "Perspectives on the life course", en Elder Glen (ed.), Life course-dynamics, trajectories and transitions, Cornell University Press, pp. 23-49.

Espíndola, Ernesto y Arturo León

2002 "La deserción escolar en América Latina: un tema prioritario para la Fainsod, Paula agenda regional" Revista Iberoamericana de Educación, 30, pp. 39-62.

2006 Embarazo y maternidad adolescente en la escuela media. Una discusión sobre las miradas deterministas de las trayectorias escolares de adolescentes 
embarazadas y madres en contextos de pobreza, Miño y Dávila Editores, Argentina.

Geldstein, Rosa y Pantelides, Edith

$200 \mathrm{R}$ Riesgo reproductivo en la adolescencia. Desigualdad social y asimetría de género, Fondo de Naciones Unidas para la Infancia, Unicef, Buenos Aires.

Geronimus, Arline y Korenman, Sanders

1992 "The socioeconomic consecuences of teen childbearing reconsidered", The Quartely Journal of Economics, vol. 37, pp. I187-I213.

Giorgi, Víctor

2006 "Construcción de la subjetividad en la exclusión" Seminario Drogas y Exclusión Social, encare, Montevideo, pp. 46-56.

Giorguli, Silvia

2006 "Deserción escolar, trabajo adolescente y estructuras familiares en México" en José Luis Lezama y José B. Morelos (coords.), Población, ciudad y medio ambiente en el México contemporáneo, CEDUA, El Colegio de México, México, pp. 235-275.

Gómez, Pio Iván, Ramiro Molina y Nina Zamberlin

201 Factores relacionados con el embarazo y la maternidad en menores de 15 años en América Latina y el Caribe, Federación Latino Americana de Sociedades de Obstetricia y Ginecología, Lima.

González de la Rocha, Mercedes

2005 "Nuevas facetas del aislamiento social: un acercamiento etnográfico" en Miguel Székely (coord.), Desmitificación y nuevos mitos sobre la pobreza, Sedesol/ciesas/anuies/porrúa, México, pp. 399-478.

González, Electra y Temístocles Molina

2007 "Características de la maternidad adolescente de madres a hijas" Revista Chilena de Obstetricia y Ginecología, 72(6), pp. 374-382.

Hoffman, Saul, Michael Foster y Frank Furstenberg

1993 "Reevaluating the costs of teenage childbearing: response to Geronimus and Korenman", Demography, 30(2), pp. 29I-296.

Horbarth, Jorge

2004 "Primer empleo de los jóvenes en México" Papeles de Población, 42, pp. I98-249.

Instituto Mexicano de la Juventud

2012 Encuesta Nacional de Juventud 20Io, Instituto Mexicano de la Juventud, (Imjuve), México. 
Jacobo, Marco Antonio et al.

2005 "El ambiente: aire, agua y áreas verdes" en Rocío Rosales Ortega et al. Diversidad urbana, politica y social en Iztapalapa, UAm-Iztapalapa, México, pp. 85-187.

Jacobson, Jon y Rebecca Maynard

I995 "Unwed mothers and long-term welfare dependency" en Addressing, illegitimacy: welfare reform options for congress, American Enterprise Institute, Washington, D.C.

Jelin, Elizabeth

1998 Pan y afectos: la transformación de las familias, FCE, Buenos Aires, pp. 83-I38. Kaztman, Rubén

200I "Seducidos y abandonados: el aislamiento social de los pobres urbanos" Revista de la CEPAL, 75, pp. I7I-I89.

Kersner, Daniel

2002 "Paisajes del dolor, senderos de esperanza" en Salud mental y derechos bumanos en el Cono Sur, Buenos Aires, pp. 235-24I.

Lewis, Oscar

I969 La vida, Joaquín Mortiz, México.

Luker, Kristin

1996 Dubious conceptions: the politics of teenage pregnancy, Harvard University, Cambridge, MA.

Menkes, Catherine, Leticia Suárez y Lepoldo Núñez

2002 "Embarazo y fecundidad adolescente en México" en Fernando Lozano (coord.), El amanecer del siglo y la población de México, Sociedad Mexicana de Demografía/crim-unam, Cuernavaca, pp. IO9-I29.

Rodríguez, Jorge y Miguel Villa

2002 Vulnerabilidad sociodemográfica: viejos y nuevos riesgos para comunidades, hogares $y$ personas, CELADE/CEPAL, Brasil.

Román, Rosario, et al.

1996 "Adolescencia, sexualidad y embarazo en el contexto de colonias populares de Hermosillo, Son.", en Tersa Lartigue y Héctor Ávila (comps.), Sexualidad y reproducción bumana en México, vol. 2, Universidad Iberoamericana/Plaza y Valdés, México, pp. 167-I82.

Sagot, Monserrat

2000 Ruta crítica de las mujeres afectadas por la violencia intrafamiliar en América Latina. Estudio de caso de diez países, ops/oms/Programa Mujer, Salud y Desarrollo, s/l. 
Salcedo, Ana Leticia

2000 "La experiencia del embarazo y su atención en adolescentes de estratos medio, popular y marginal" en Claudio Stern y Carlos Echarri (comps.) Salud reproductiva y sociedad. Resultado de investigación, El Colegio de México, México, pp. 199-23I.

Salcedo, Soledad

2004 "Perfil de la marginación en el Distrito Federal" en Secretaría de Desarrollo Social, Consejo de Desarrollo Social del Distrito Federal, Pobreza, desigualdad y marginación en el Distrito Federal, Secretaría de Desarrollo Social del Distrito Federal, México, pp. 59-66.

2008 "Construcción del índice de marginación del Distrito Federal y su utilización en las políticas sociales" en Beatriz Figueroa (coord.), El dato en cuestión. Un análisis de las cifras sociodemográficas, El Colegio de México, México, pp. 74I-773.

Santana, Rosalinda, Roberto Sánchez y Emilio Herrera

1998 "El maltrato infantilः un problema mundial", Salud Pública de México, 4O(I), pp. 58-65.

Saraví, Gonzalo

2004 "Segregación urbana y espacio público: los jóvenes en enclaves de pobreza estructural" Revista de la CEPAL, 83, pp. 33-48.

Stern, Claudio

I995 "Embarazo adolescente: significado e implicaciones para distintos sectores sociales" Demos, 8, pp. II-I2.

2004 "Vulnerabilidad social y embarazo adolescente en México" Papeles de Población, Io(39), enero-marzo, pp. 129-158.

Stern, Claudio y G. Elizabeth García

200 "Hacia un nuevo enfoque en el campo del embarazo adolescente" en Claudio Stern y Juan Guillermo Figueroa (coords.), Sexualidad y salud reproductiva. Avances y retos para la investigación, El Colegio de México, México, pp. 331-364.

Stern, Claudio y Catherine Menkes

2008 "Embarazo adolescente y estratificación social", en Susana Lerner y Ivonne Szasz (comps.), Salud reproductiva y condiciones de vida en México, vol. I, El Colegio de México, México, pp. 347-396.

Szasz, Ivonne

1998 "Sexualidad y género: algunas experiencias de investigación en México", Debate Feminista, año 9, vol. 18, octubre, pp. 77-104. 
Torres, Marta 200I La violencia en casa, Editorial Croma, México.

Townsend, Peter

1979 Poverty in the United Kingdom: A Survey of Household Resources and Standards of Living, University of California Press, Berkeley-Los Angeles.

Tunón, Esperanza y Austreberta Nazar

2002 "Pobreza y embarazo adolescente en Chiapas" en Fernando Lozano (coord.), El amanecer del siglo y la población de México, SOMEDE/CRIMunam, Cuernavaca, pp. 183-197.

Valentine, Charles

1970 La cultura de la pobreza, Amorrortu, Buenos Aires.

Welti, Carlos

2005 "Inicio de la vida sexual y reproductiva" Papeles de Población, 45, pp. I43-176.

Zamudio, Carlos Alberto

2007 Las redes del narcomenudeo. Cómo se reproducen el consumo y el comercio de drogas ilícitas entre jóvenes de barrios marginados, tesis de licenciatura inédita, ENAH, México.

Ziccardi, Alicia

1998 Gobernabilidad y participación ciudadana en la ciudad capital, Miguel Ángel Porrúa/Instituto de Investigaciones Sociales-unam, México, $237 \mathrm{pp}$. 